East African Medical Journal Vol. 81 No. 7 July 2004

POST TRAUMATIC STRESS DISORDER AMONG MOTOR VEHICLE ACCIDENT SURVIVORS ATTENDING THE ORTHOPAEDIC AND TRAUMA CLINIC AT KENYATTA NATIONAL HOSPITAL, NAIROBI

F. A. Ongecha-Owuor, MBChB, MMed (Psych) (Nrb), Psychiatrist, Mathari Hospital, P.O. Box 34646, 00100 Nairobi, D. M. Kathuku, MBChB, MMed (Psych) (Nrb), Av Med (USA), Senior Lecturer, C. J. Othieno, MBChB, MMed (Psych) (Nrb), Senior Lecturer, Department of Psychiatry, College of Health Sciences, University of Nairobi, P.O. Box 19676 Nairobi, Kenya, and D. M. Ndetei, MBChB (Nrb), DPM (Lond), MRCPsych (UK), MD (Nrb), Professor, Department of Psychiatry, College of Health Sciences, University of Nairobi and Director, Africa Mental Health Foundation, Nairobi Kenya

Request for reprints to: Dr. F. A. Ongecha-Owuor, Mathari Hospital, P.O. Box 34646, 00100, Nairobi, Kenya

\title{
POST TRAUMATIC STRESS DISORDER AMONG MOTOR VEHICLE ACCIDENT SURVIVORS ATTENDING THE ORTHOPAEDIC AND TRAUMA CLINIC AT KENYATTA NATIONAL HOSPITAL, NAIROBI
}

\section{F. A. ONGECHA-OWUOR, D. M. KATHUKU, C. J. OTHIENO and D. M. NDETEI}

\begin{abstract}
Objectives: To determine the prevalence rate of post traumatic stress disorder (PTSD) and associated risk factors among motor vehicle accident (MVA) survivors attending the orthopaedic and trauma clinic at Kenyatta National Hospital, Nairobi.

Design: A cross-sectional study.

Setting: Kenyatta National Hospital, Nairobi.

Subjects: One hundred and ninety seven adult males and sixty seven female patients. Method: The 264 patients were interviewed using a questionnaire to collect the sociodemographic data, the Self Rating Questionnaire (SRQ) and the Impact of Event Scale -Revised (IES-R). Diagnosis was made using the Diagnostic and Statistical Manual (DSM-IV).

Results: The mean age was $34.63 \pm 12.71$ years (range $18-65)$. Overall, the prevalence rate of PTSD was $13.3 \%$. None of the cases had been previously diagnosed as having PTSD. Females had a higher rate of $17.9 \%(n=67)$, compared to the males $11.7 \%$ $(n=197)$. The majority of those with PTSD $(42.9 \%)$ were young, 20 - 29 years. Other risk factors were having post-primary education $(62.9 \%)$, experiencing the first motor vehicle accident $(14.1 \%)$, previous psychiatric illness, and other medical illnesses. The type of accident, role/status and immediate reactions to the accident were not significant. Conclusions: PTSD following motor vehicle accidents is common. Although the MVA survivors do develop significant rates of PTSD, it is not easy to identify those at risk but some of the parameters documented in this study may help. A multi disciplinary approach is therefore essential in the management of the RTA survivors at the orthopaedic and trauma clinics if their physical and psychological needs are to be adequately addressed
\end{abstract}

\section{INTRODUCTION}

In recent years there has been a global increase in reports dealing with the psychiatric sequalae of trauma. Studies done in the United States of America found that motor vehicle accidents (MVA) were the single leading cause of post traumatic stress disorder (PTSD) in the general population(1). Motor vehicle accidents therefore are a recognised form of trauma and mental health difficulties may occur even in those who have not suffered physical injuries(2,3). PTSD is a pervasive anxiety disorder that is currently defined by the existence of three clusters of symptoms (reexperiencing, avoidance and numbing, and hyper arousal) persisting for at least one month, following a traumatic event(4). The three types recognised are the acute (with symptom duration of 1-3 months), chronic (symptom duration of three or more months) and delayed onset if the onset of symptoms occurs at least six months after the traumatic event.
The expansion of the road network in Kenya and the increase in the number of motor vehicles without adequate quality control has led to a rapid rise in the number of road traffic accidents. For instance, in 1963, there were 4,784 casualties with 548 deaths while in 1998 there were 33,924 casualties with 3,127 deaths $(5,6)$. Little is known about the detailed consequences for mental health or other aspects of quality of life after motor vehicle accidents in the local setting. No study in Kenya has so far addressed the psychological sequelae related to MVAs in particular. In general, and inspite of many traumatic experiences and events in Kenya, such as the American Embassy Bombing in 1998, tribal clashes, school fire tragedies, there is a dearth of published documentation on psychotrauma in Kenya. The few studies documented include; traumatic grief among parents of learners who perished in a school fire tragedy in Kenya(7), the effects of the media among Nairobi residents three months after the Nairobi bomb blast (8) and psychopathology pursuant to traumatic 
closed head injury(9). None of these studies focused specifically on PTSD as a clinical entity. However, a case of PTSD was reported in 2002(10). The present study sought to determine the prevalence of PTSD among motor vehicle accident survivors and the correlates associated with the development of this psychopathology.

Estimates of the prevalence rate of PTSD following MVAs vary widely depending on the methodology and population studied(11). In a study of PTSD among 158 survivors of MVAs (one to four months after the accident), using the Clinician Administered PTSD Scale (CAPS), a prevalence rate of 39.2\% was found(12). Another study using different tools, the Present State Examination (PSE) and the Diagnostic and Statistical Manual (DSM-III R) (13) found prevalence rates of 8\% and $11.1 \%(\mathrm{n}=188)$ at three and 12 months respectively after the accident(14). In Australia, Green, et al.(15) using the DIS, General Health Questionnaire (GHQ) and the DSM $111 \mathrm{R}$ found rates of $8.3 \%$ and $25 \%$ at one and eight months respectively. High scores on the intrusion and avoidance subscales tended to be the most consistent predictor of PTSD(15-17). Others were horrific and intrusive memories at initial assessment in the emergency room(13,18). Studies involving other traumatic events have identified the following independent predictors for the development of PTSD: female gender, currently married for men, previously married for women, pre-existing major depression, anxiety disorder, substance abuse, lower socio-economic status, family history of anxiety or antisocial behaviour, previous exposure to trauma (childhood abuse and early separation from parent), lack of post exposure social support and adjustment (19-22).

\section{MATERIALS AND METHODS}

The study was conducted at the Kenyatta National Hospital's orthopaedic and trauma clinic. The referral hospital's clinic attends to 70 patients in each of the three weekly sessions. An estimated $50 \%$ of the patients who attend have motor vehicle accident related cases. Systematic sampling was used and every fifth patient in the queue who satisfied the inclusion criteria was recruited for the study. These were: those aged above 18 years and had an accident at least one month prior to the date of the interview. After obtaining informed consent from the patients the following instruments were administered: the socio-demographic data questionnaire, the Self-Rating Questionnaire (SRQ)(23) and the Impact of Event Scale - revised edition (IES-R)(24). Thereafter an experienced mental health clinicians used the Structured Psychiatric Interview (SPI)(25) and the Diagnostic and Statistical Manual (DSM IV)(4) to make a diagnosis. Data was analysed using the Epiinfo version 6.0. The data is presented using frequencies and statistical differences tested using the Chi-square tests. The level of significance was set at $\mathrm{p} \leq 0.05$

\section{RESULTS}

Two hundred and sixty four patients (197 males and 67 females) were enrolled for the study. The mean age was $34.63 \pm 12.71$ years (range 18-65) and the mode $=20-29$ years. Most of the participants were married $(59.4 \% \mathrm{n}=158)$, and of post primary education $(50.4 \%, \mathrm{n}=133)$.

Table 1

Socio-demographic characteristics of motor vehicle accident (MVA) survivors attending the orthopaedic clinic at Kenyatta National Hospital $(n=264)$

\begin{tabular}{|c|c|c|c|c|c|c|}
\hline \multirow[t]{2}{*}{ Characteristic } & \multicolumn{2}{|c|}{ PTSD } & \multicolumn{2}{|c|}{ NPTSD } & \multicolumn{2}{|c|}{ Total } \\
\hline & No. & $\%$ & No. & $\%$ & No. & $\%$ \\
\hline \multicolumn{7}{|l|}{ Gender } \\
\hline Male & 23 & 8.7 & 174 & 66.0 & 197 & 74.6 \\
\hline Female & 12 & 4.5 & 55 & 20.8 & 67 & 25.4 \\
\hline$X^{2}=1.7$ & $\mathrm{df}=1$ & $\mathrm{p}<0.05$ & & & & \\
\hline Age group & $\mathrm{n}$ & $\%$ & $\mathrm{n}$ & $\%$ & $\mathrm{n}$ & $\%$ \\
\hline$<20$ & 2 & 08 & 17 & 6.4 & 19 & 7.2 \\
\hline $20-29$ & 15 & 5.7 & 72 & 27.2 & 87 & 33 \\
\hline $30-39$ & 9 & 34 & 62 & 23.5 & 71 & 26.9 \\
\hline $40-49$ & 7 & 2.7 & 38 & 14.4 & 45 & 17.0 \\
\hline$\geq 50$ & 2 & 0.8 & 40 & 15.2 & 42 & 15.9 \\
\hline$X^{2}=4.3$ & $\mathrm{df}=4$ & $\mathrm{p}<=0.05$ & & & & \\
\hline \multicolumn{7}{|l|}{ Marital status } \\
\hline Married & 22 & 8.3 & 136 & 51.5 & 158 & 59.8 \\
\hline Previously married & 3 & 1.1 & 11 & 4.2 & 14 & 5.3 \\
\hline Never married & 10 & 3.8 & 82 & 31.1 & 92 & 34.8 \\
\hline$X^{2}=14.52$ & $\mathrm{df}=2$ & $\mathrm{p}>0.05$ & & & & \\
\hline \multicolumn{7}{|l|}{ Occupation } \\
\hline Professional & 5 & 1.9 & 26 & 9.8 & 30 & 11.4 \\
\hline Skilled & 14 & 5.3 & 71 & 26.9 & 85 & 32.2 \\
\hline Semi-skilled & 2 & 0.8 & 27 & 10.2 & 29 & 11.0 \\
\hline Unskilled & 11 & 4.2 & 98 & 37.1 & 109 & 41.3 \\
\hline Student & 3 & 1.1 & 7 & 2.7 & 10 & 3.8 \\
\hline$X^{2}=6.4$ & $\mathrm{df}=4$ & $\mathrm{p}<0.05$ & & & & \\
\hline
\end{tabular}




\begin{tabular}{lcccccc} 
Education & & & & & \\
$\quad$ None & 2 & 0.8 & 15 & 5.7 & 17 & 6.4 \\
Primary & 11 & 4.2 & 103 & 39.0 & 114 & 43.2 \\
Secondary & 12 & 4.5 & 74 & 28.0 & 86 & 32.6 \\
College/University & 10 & 3.8 & 37 & 14.4 & 47 & 17.8 \\
$\mathrm{X}^{2}=4.0$ & $\mathrm{df}=3$ & $\mathrm{p}<0.05$ & & & & \\
\hline
\end{tabular}

Table 2

Past medical history in relation to PTSD among the motor vehicle (MVA) survivors attending the orthopaedic clinic at Kenyatta National Hospital $(n=264)$

\begin{tabular}{|c|c|c|c|c|c|c|}
\hline \multirow[t]{2}{*}{ Characteristic } & \multicolumn{2}{|c|}{ PTSD } & \multicolumn{2}{|c|}{ NPTSD } & \multicolumn{2}{|c|}{ Total } \\
\hline & No. & $\%$ & No. & $\%$ & No. & $\%$ \\
\hline \multicolumn{7}{|l|}{ Past surgical history } \\
\hline Yes & 7 & 2.7 & 15 & 5.7 & 22 & 8.3 \\
\hline No & 28 & 10.6 & 214 & 81.1 & 242 & 91.7 \\
\hline$X^{2}=7.3$ & $\mathrm{df}=1$ & $\mathrm{p}>0.05$ & & & & \\
\hline \multicolumn{7}{|c|}{ Other past physical illness } \\
\hline Yes & 8 & 3.0 & 36 & 13.6 & 44 & 16.7 \\
\hline No & 27 & 10.2 & 193 & 73.1 & 220 & 83.3 \\
\hline$X^{2}=1.15$ & $\mathrm{df}=1$ & $\mathrm{P}<0.05$ & & & & \\
\hline \multicolumn{7}{|l|}{ Past psychiatric illness } \\
\hline Yes & 1 & 0.4 & 2 & 0.8 & 3 & 1.1 \\
\hline No & 33 & 12.5 & 224 & 84.8 & 258 & 97.7 \\
\hline Missing & 1 & 0.4 & 3 & 1.1 & 4 & 1.5 \\
\hline$X^{2}=1.65$ & $\mathrm{df}=2$ & $\mathrm{p}<0.05$ & & & & \\
\hline \multicolumn{7}{|l|}{ Previous MVA } \\
\hline Yes & 1 & 0.4 & 22 & 8.3 & 23 & 8.7 \\
\hline No & 34 & 12.9 & 207 & 78.4 & 241 & 91.3 \\
\hline$X^{2}=1.74$ & $\mathrm{df}=1$ & $\mathrm{p}<0.05$ & & & & \\
\hline
\end{tabular}

Table 3

Accident variables among, the motor vehicle accident (MVA) survivors attending the orthopaedic clinic at Kenyatta National Hospital $(n=264)$

\begin{tabular}{|c|c|c|c|c|c|c|}
\hline \multirow[t]{2}{*}{ Characteristic } & \multicolumn{2}{|c|}{ PTSD } & \multicolumn{2}{|c|}{ NPTSD } & \multicolumn{2}{|c|}{ Total } \\
\hline & No. & $\%$ & No. & $\%$ & No. & $\%$ \\
\hline \multicolumn{7}{|l|}{$\begin{array}{l}\text { Duration from time } \\
\text { of accident (months) }\end{array}$} \\
\hline $1-3$ & 11 & 4.2 & 119 & 45.1 & 130 & 49.2 \\
\hline $3-6$ & 10 & 3.8 & 38 & 14.4 & 48 & 18.2 \\
\hline $6-12$ & 9 & 3.4 & 38 & 14.4 & 47 & 17.8 \\
\hline$>12$ & 5 & 1.9 & 34 & 12.9 & 39 & 14.8 \\
\hline$X^{2}=6.38$ & $\mathrm{df}=3$ & $\mathrm{p}<0.05$ & & & & \\
\hline \multicolumn{7}{|l|}{ Type of accident } \\
\hline MV/MV mobile & 10 & 3.4 & 142 & 45.1 & 152 & 59.8 \\
\hline MV/MV stationary & 2 & 0.8 & 4 & 1.1 & 6 & 5.3 \\
\hline $\mathrm{MV}+$ pile up & 1 & 0.4 & 0 & 0 & 1 & 0.4 \\
\hline MV roll (single) & 7 & 2.7 & 23 & 8.7 & 30 & 11.4 \\
\hline Other & 15 & 5.7 & 59 & 22.3 & 74 & 28.0 \\
\hline Missing & 0 & 0 & 1 & 0.4 & 1 & 0.4 \\
\hline$X^{2}=16.57$ & $\mathrm{df}=5$ & $\mathrm{P}>0.05$ & & & & \\
\hline \multicolumn{7}{|l|}{ Role/status } \\
\hline Passenger & 17 & 6.4 & 112 & 42.4 & 129 & 48.9 \\
\hline Driver & 5 & 1.9 & 21 & 8.0 & 26 & 9.8 \\
\hline Pedestrian & 12 & 4.5 & 96 & 36.4 & 108 & 40.9 \\
\hline$X^{2}=17.34$ & $\mathrm{df}=3$ & $\mathrm{p}>0.05$ & & & & \\
\hline
\end{tabular}




\begin{tabular}{|c|c|c|c|c|c|c|}
\hline \multicolumn{7}{|l|}{ Immediate reaction } \\
\hline None & 5 & 1.9 & 65 & 24.6 & 70 & 26.5 \\
\hline Slightly injured & 8 & 3.0 & 48 & 18.2 & 56 & 21.2 \\
\hline Maimed & 8 & 3.0 & 23 & 8.7 & 31 & 11.7 \\
\hline Thoughts of death & 14 & 5.3 & 91 & 34.5 & 105 & 39.8 \\
\hline$X^{2}=68.32$ & $\mathrm{df}=4$ & $\mathrm{p}>0.05$ & & & & \\
\hline \multicolumn{7}{|l|}{ Was there } \\
\hline Yes & 7 & 2.7 & 40 & 15.2 & 47 & 17.8 \\
\hline No & 27 & 10.2 & 179 & 67.8 & 206 & 78.0 \\
\hline Missing & 1 & 0.4 & 10 & 3.8 & 11 & 4.2 \\
\hline$X^{2}=1.96$ & $\mathrm{df}=2$ & $\mathrm{p}<0.05$ & & & & \\
\hline
\end{tabular}

$\mathrm{MV}=$ motor vehicle; $\mathrm{OV}=$ other vehicle

Using the DSM-IV diagnostic criteria for PTSD, an overall prevalence of 35/264 (13.3\%) was found among the patients interviewed. The rate was higher among the females: $12 / 67$ patients (17.9\%) met the diagnostic criteria used compared to $23 / 197$ males $(11.7 \%)$ in the study $(\mathrm{p}<0.05)$. PTSD was also significantly more common among the young patients. The majority, $87 / 264(33 \%)$ of the MVA survivors were in the age group $20-29$ years. Of the 87 survivors, $15(17.2 \%)$ developed PTSD. Thus nearly half 17/35(42.9\%) of the total PTSD cases were in this age group.

Those previously married had the highest rate of PTSD 3/14 (21.4\%) followed by those who were currently married 22/158 (13.9\%). The lowest rates were seen among those who had never been married $10 / 92(10.9 \%)$. The differences were, however, not statistically significant. Post-primary education was associated with a higher risk of PTSD 22/264 (8.3\%) compared to the rate in those with only primary education 11/264 (4.2\%) $(\mathrm{p}<0.05)$ (Table 1). High rates of PTSD were also noted in those with a previous history of surgery $7 / 22(31.8 \%)$ but this was not statistically significant. However, those with history of other past physical illness had significantly higher rates of PTSD (Table 2). Another significant finding was that a third of those with prior psychiatric illness developed PTSD. Other variables considered were the duration from time of accident, type of accident, role/status, immediate reaction to the accident, and whether or not there was a death. Those who had an accident within the past 6-12 months prior to the interview date were more likely to develop PTSD compared to those whose accidents occurred less than six months or more than 12 months before the interview date. The accidents were classified as shown in Table 3. No specific type of accident was associated with an increased risk of PTSD. Out of the 264 subjects, 26(9.8\%) were drivers, $129(48.9 \%)$ passengers and $108(40.9 \%)$ pedestrians. Of the 26 drivers, five (19.0\%) developed PTSD while only $17 / 129(13.2 \%)$ and $12 / 108(11.1 \%)$ passengers and pedestrians respectively developed PTSD. The differences were not statistically significant (Table 3 ). The immediate reaction to the accident also could not distinguish between those who did not and those who subsequently developed PTSD. However if a death occurred as a result of the accident then PTSD was more likely to develop compared to when no death had occurred.

\section{DISCUSSION}

The study was conducted at a trauma and orthopaedic clinic of a referral hospital and so had a biased sample. Nevertheless the age distribution of those studied reflects that of the general population in that they were mostly young. The predominance of males in the sample could not be easily explained. Perhaps they were more likely to be motor vehicle drivers and hence more prone to injury compared to the females. The overall prevalence of PTSD (13.3\%) is comparable to that found in the developed countries: range $7-39 \%(13,16,26,27)$. As in the other studies(20) the females were at a greater risk of developing PTSD. Among those who developed PTSD, $42.9 \%$ were in the age group 20 - 29 years and $25.7 \%$ in the $30-39$ years (Table 1). It appears therefore that the younger subjects are more prone to developing PTSD than the older subjects. It is possible that the older subjects had learned coping mechanisms from past experience. Despite the significant number of patients with PTSD none had been previously diagnosed. All were attending the clinics purely for their physical injuries.

Marriage was identified as a possible risk factor especially for the males where $(81.85 \%)$ of those having the diagnoses of PTSD were married. For the females, $21.4 \%$ of those affected had been previously married, (divorced, separated or widowed). Though these factors were associated with a greater risk and are similar to those of other studies on traumatic events other than MVAs(20) they were not statistically significant. Those with post primary education, professionals and students had higher rates of PTSD compared to those with lower levels of education $(p<0.05)$. An explanation for this could be that the groups more affected had greater understanding of the possible consequences of the accident and feared that their life goals and ambitions could be adversely affected.

The majority of those who developed PTSD (71.4\%) had no family history of psychiatric illness, but $23.3 \%$ had a family history of alcohol abuse. 
Among those patients with PTSD, 33.3\% had past psychiatric illness. Several workers(19-22) have noted, in particular, that pre-existing major depressive disorder (MDD) and anxiety disorders were specific risk factors for developing PTSD. In the present study no specific psychiatric disorder was associated with a greater risk of developing PTSD but in general those who had suffered psychiatric illness in the past had a greater risk of developing PTSD. Similarly those who had other physical illnesses were at a greater risk. Perhaps the accident acted as a further stressor to these individuals who were already overwhelmed.

In the present study the subsequent development of PTSD did not seem to be influenced by the type of accident, role/status or the immediate reaction to the accident. This is in contrast to the findings of other workers $(13,16)$ who reported that "horrific and intensive memories" at the initial assessment, perceived threat of life in the MVA and exposure or witnessing the accident predicted the occurrence of PTSD.

In conclusion, this study has shown that MVA survivors do develop significant rates of PTSD and it is not easy to identify those at risk though some of the parameters documented in this study may help. A multidisciplinary approach is therefore essential in the management of the RTA survivors at the orthopaedic and trauma clinics if their physical and psychological needs are to be adequately addressed. Given that more than 12 months after the accident $5 / 39$ (12.8\%) were still suffering from PTSD it may be necessary for future management teams to look into a possibility of compensating these patients. More important is the prevention of road traffic accidents by implementing road safety measures such as safety belts, speed governors, improved road infrastructure and stricter law enforcement measures on traffic offenders which will go along way in reducing MVA and therefore PTSD.

\section{ACKNOWLEDGEMENTS}

To the Director of Kenyatta National Hospital, the entire staff at the Orthopaedic and trauma clinic for allowing us to carry out the study and permission to publish this paper, the patients for their co-operation, Mr. W. O. Odero for statistical analysis.

\section{REFERENCES}

1. Norris, F. H. Epidemiology of Trauma: frequency and impact of different potentially events on different demographic groups. J. Consulting and Clinical Psych. 1992; 60:406-418.

2. O'Brien, L. S. Traumatic Events and Mental Health. University Press. Cambridge. 1998.

3. Blanchard, E. B., Hickling, E. J., Taylor, A. E. and Ross, W. R. Psychiatric morbidity associated with motor vehicle accidents. J. Nervous and Mental Dis. 1995; 183:495-504.

4. American Psychiatric Association. Diagnostic and Statistical Manual 4th Edition (DSV-IV). Washington DC.1994.

5. Central Bureau of Statistics. Statistical Abstract. Kenya Government Press, Nairobi. 1999.
6. Central Bureau of Statistics. Economic Survey. Kenya Government Press, Nairobi. 2001.

7. Ndetei, D.M., Othieno, C., Gakinya, B., et al. Traumatic grief in Kenyan bereaved parents following the Kyanguli school fire tragedy. World Psychiatry. 2004; 3:50-53.

8. Njenga, F.G., Nyamai, C.M. and Kigamwa, P. Terrorist bombing at the USA Embassy in Nairobi: The media response. East Afr. Med. J. 2003; 80:159-164.

9. Sebit, M. B. A prospective study of psychiatric sequelae after closed head injury among patients treated at the Kenyatta National Hospital in Nairobi, Kenya. PhD thesis. University of Nairobi. 1992.

10. Nyamai, C.M. and Njenga, F.G. Post traumatic stress disorder: A case report. East Afr. Med. J. 2002; 77:228-230.

11. Kessler, R. C. The epidemiology, course and pharmacoeconomics of post traumatic stress disorder. Intern. J Neuropsychophamacology. 2000; 3:S 54. Abstract S. 34.1.

12. Blanchard, E. B. and Hickling, E. J. After the crash: assessment and treatment of motor vehicle accident survivors. American Psychological Association, Washington DC. 1997.

13. American Psychiatric Association. Diagnostic and Statistical Manual 3rd Edition (DSM-III). Washington DC. 1980.

14. Mayou, R., Bryant, B. and Duthie, R. Psychiatric consequences of road traffic accidents. Brit. Med. J. 1993; 307:647-651.

15. Green, M. M., McFarlane, A. C., Hunter, C. E. and Griggs, W. M. Undiagnosed post traumatic stress disorder following motor vehicle accidents. Med. J. Australia. 1993; 159:529-534.

16. Feinstein, A. and Dolan, R. Predictors of PTSD following physical trauma: an examination of the stressor criterion. Psych. Med. 1991; 21:85-91.

17. Epstein, R. S. Avoidant symptoms cloaking the diagnosis of posttraumatic stress disorder in patients with severe accidental injury. J. Traumatic Stress. 1993; 6:451-458.

18. Scott, J. R., Wilhelm, K. L., Nothrop, L. M. E., et al. An investigation of post traumatic stress disorder in vehicular accident survivors. Paper presented at the 26th Annual meeting of the Asssociation for Advancement of Behaviour Therapy, Boston, MA. November 1992.

19. Breslau, N., Davis, G. C., Andreski, P. and Peterson, E. Traumatic events and post traumatic stress disorder in an urban population of young adults. Arch. General Psych. 1991; 48:216-222.

20. Kessler, R. C., Sonnega, A., Bromet, E. J., Hughes, M. and Nelson, C. B. Posttraumatic stress disorder in the National comorbidity survey. Arch. General Psych. 1995; 52:1048-1060.

21. Kessler, R. C., Breslau, N. and Chilcoat, H. D. Traumatic and post traumatic stress disorder in the community: the 1996 Detroit Area Survey of Trauma. Arch. General Psych. 1998; 55:626-631.

22. Ursano, R. J., Fullerton, C. S. and Epstein, R. S. Acute and chronic post traumatic stress disorder in motor vehicle accident victims. Amer. J. Psych. 1991; 156:589-595.

23. Harding, T. W., Dearango, M. V., Baltazar, J., et al. Mental disorders in primary health care: A study of their frequency and diagnosis in four developing countries. Psych. Med. 1980; 10:231-234.

24. Weiss, D. S. and Marmar, C. R. The Impact of Event Scale - Revised. In Wilson J P and Keane T M (Eds.) Assessing Psychological Trauma and PTSD: A Practitioners Handbook pp 399-411. Guilford, New York. 1997.

25. Goldberg, D. P., Cooper, B., Eastwood, M. R., Kendward, H. B. and Shepherd, M. A. Standard psychiatric interview for use in community survey. Brit. J. Preventive and Social Med. 1970; 24:18-23.

26. Brom, D., Kleber, R.J. and Hofman, M.C. Victims of traffic accidents: incidence and prevention of post traumatic stress disorder. J. Clin. Psych. 1993; 49:131-140.

27. Blanchard, E.B., Hickling, E.J., Taylor, A.E., Loss, W.R., Forneris, C.A., and Jaccard, J. Who develops PTSD from motor vehicle accidents? Behaviour Res. Therapy. 1996; 34:1-10. 